\title{
Stability, Adaptability Analysis of Wheat Genotypes by AMMI with BLUP for Restricted Irrigated Multi Location Trials in Peninsular Zone of India
}

\author{
Ajay Verma*, Gyanendra Pratap Singh \\ ICAR-Indian Institute of Wheat \& Barley Research, Karnal, India \\ Email: *ajay.verma1@icar.gov.in
}

How to cite this paper: Verma, A. and Singh, G.P. (2021) Stability, Adaptability Analysis of Wheat Genotypes by AMMI with BLUP for Restricted Irrigated Multi Location Trials in Peninsular Zone of India. Agricultural Sciences, 12, 198-212. https://doi.org/10.4236/as.2021.123013

Received: January 22, 2021

Accepted: March 6, 2021

Published: March 9, 2021

Copyright ( 2021 by author(s) and Scientific Research Publishing Inc. This work is licensed under the Creative Commons Attribution International License (CC BY 4.0).

http://creativecommons.org/licenses/by/4.0/ (c) (i) Open Access

\begin{abstract}
Highly significant effects of the environment (E), GxE interaction, and genotypes $(G)$ had been observed by AMMI analysis for wheat genotypes evaluated under restricted irrigated timely sown multi-location trials in Peninsular zone of the country during 2018-19 and 2019-20 cropping seasons. Ranking of genotypes had changed with the number of interaction Principal Component Axes (IPCA's) included for the calculation of Additive Main and Multiplicative Interaction (AMMI) based as well as Weighted Average of Absolute Scores (WAASB) stability measures. The Superiority indexes while assigning more weights to yield as compared to stability measures pointed out wheat genotypes MACS6695, HI1605, NIAW3170 \& MACS6696 would maintain high yield and stable performance for the first year. Adaptability measures as per various averages expressed deviation from other measures and maintained right angle with MASV1 and stability measures. Moreover, the Superiority indexes as per various averages clustered in the same quadrant. Second-year of the study observed MP1358, NIAW3170, NIDW1149, MACS4087 wheat genotypes pointed by Superiority indexes. Adaptability measures as per arithmetic, geometric and harmonic means expressed strong bondage and grouped in a separate quadrant. This cluster maintained the right angle with stability measures and cluster of Superiority indexes as per various averages placed in a different quadrant. Superiority indexes would provide the reliable estimates of genotype performance in future studies in a biplot as considered all of significant IPCA's.
\end{abstract}

\section{Keywords}

AMMI Measures, BLUP, WAASB, SI, Biplot Analysis 


\section{Introduction}

An efficient assessment of GxE interaction had been emphasized to determine the yield potential and stability of the genotypes under multi location trials [1]. Earlier the regression techniques employed for the analyses of GxE interaction adequately described the linear behavior of genotypes over different environments [2]. AMMI model had been proved as a useful analytic approach for linear and non-linear response of genotypes over the environmental conditions [3] [4]. Prediction of genotypes yield behaviour would be better explained by genotype's random interaction with a specific environment [5]. The prediction of random variables has been carried out by Best Linear Unbiased Prediction (BLUP) [6]. The need was felt to employ better models and techniques like, AMMI and BLUP for valid and meaningful predictions about genotypic performance [7]. Usually these two analytic approaches have been used separately in the field evaluation of genotypes under multi location trials [8]. The simultaneous consideration of yield and stability in a single measure had been advocated [9]. Simultaneous Selection Indices had been developed by adding the corresponding ranks as per stability measure and yield performance of genotypes [10], [11]. The benefits of these two important techniques incorporated into a Superiority Index measure for the stability and adaptability of genotypes [12]. The present study dealt with the analysis of GxE interaction with emphasis on yield stability by AMMI along with BLUP techniques for restricted irrigation evaluation of wheat genotypes in the Peninsular zone of India.

\section{Materials and Methods}

Maharashtra and Karnataka states jointly represent the Peninsular zone and three species of wheat viz $T$. aestivum, $T$. durum, and $T$. dicoccum are cultivated in this zone. Twelve promising wheat genotypes under advanced trials were evaluated at eight major locations and ten genotypes at eight locations during 2018-19 and 2019-20 respectively. Field trials were laid out in randomized complete block designs with four replications. Recommended agronomic practices were followed to harvest good yield. The location details and parentage of evaluated genotypes were reflected in Table $1 \&$ Table 2 for ready reference.

Stability measure as Weighted Average of Absolute Scores has been calculated as

$$
\mathrm{WAASB}=\sum_{k=1}^{p}\left|\mathrm{IPCA}_{i k} \times \mathrm{EP}_{k}\right| / \sum_{k=1}^{p} \mathrm{EP}_{k}
$$

where $\mathrm{WAASB}_{i}$ was the weighted average of absolute scores of the $i$ th genotype (or environment); IPCA $_{i k}$ the score of the $i$ th genotype (or environment) in the $k$ th IPCA, and $\mathrm{EP}_{k}$ was the amount of the variance explained by the $k$ th IPCA. Superiority index allowed variable weights to yield and stability measure (WAASB) to select genotypes that combine high performance and stability as

$$
\mathrm{SI}=\frac{\left(r G_{i} \times \theta_{Y}\right)+\left(r W_{i} \times \theta_{S}\right)}{\left(\theta_{Y}+\theta_{S}\right)} ;
$$


Table 1. Details of location and parentage of evaluated wheat genotypes (2018-19).

\begin{tabular}{|c|c|c|c|c|c|c|}
\hline Code & Genotype & Parentage & Location & Latitude & Longitude & Mean sea level \\
\hline G1 & NIAW3170 & (SKOLL/ROLF07) & Niphad & $20^{\circ} 4^{\prime} \mathrm{N}$ & $74^{\circ} 6^{\prime} \mathrm{E}$ & 551 \\
\hline G2 & GW1346 & (GW1236/AR06-3) & Pune & $18^{\circ} 31^{\prime} \mathrm{N}$ & $73^{\circ} 51^{\prime} \mathrm{E}$ & 562 \\
\hline G3 & MACS4058 & (MACS3125/AKDW2997-16//MACS3125) & Parbhani & $19^{\circ} 15^{\prime} \mathrm{N}$ & $76^{\circ} 46^{\prime} \mathrm{E}$ & 413 \\
\hline G4 & DBW93 & (WHEAR/TUKURU//WHEAR) & Savalivihir & $19^{\circ} 48^{\prime} \mathrm{N}$ & $74^{\circ} 27^{\prime} \mathrm{E}$ & 519.42 \\
\hline G5 & HI8805 & (IWP5070/HI8638//HI8663) & Dharwad & $15^{\circ} 27^{\prime} \mathrm{N}$ & $75^{\circ} 0^{\prime} \mathrm{E}$ & 724 \\
\hline G6 & AKDW2997-16 & (CPAN6140/RAJ1555) & Bailahongal & $15^{\circ} 48^{\prime} \mathrm{N}$ & $74^{\circ} 51^{\prime} \mathrm{E}$ & 696.61 \\
\hline G7 & MACS6695 & $(\mathrm{NI} 5439 * 2 / \mathrm{HD} 2934)$ & Nippani & $16^{\circ} 23^{\prime} \mathrm{N}$ & $74^{\circ} 22^{\prime} \mathrm{E}$ & 606 \\
\hline G8 & UAS446 & (DWR185/DWR2006//UAS419) & Bagalkot & $16^{\circ} 10^{\prime} \mathrm{N}$ & $75^{\circ} 42^{\prime} \mathrm{E}$ & 524 \\
\hline G9 & HI1605 & $\begin{array}{c}\text { (BOW/VEE/5/ND/VG9144//KAL//BB/3/YACO/4/CHIL/6/ } \\
\text { CASKOR/3/CROC_1/A.SQUARROSA(224)//OPATA/7/ } \\
\text { PASTOR//MILAN/KAUZ/3/BAV92 }\end{array}$ & & & & \\
\hline G10 & MACS6696 & (NI5439/HD2934) & & & & \\
\hline G11 & NIDW1149 & (NIDW295/NIDW15) & & & & \\
\hline G12 & HI8802 & (HI8627/HI8653) & & & & \\
\hline
\end{tabular}

Table 2. Details of location and parentage of evaluated wheat genotypes (2019-20).

\begin{tabular}{|c|c|c|c|c|c|c|}
\hline Code & Genotype & Parentage & Location & Latitude & Longitude & Mean sea level \\
\hline G1 & NIDW1149 & (NIDW295/NIDW15) & Niphad & $20^{\circ} 4^{\prime} \mathrm{N}$ & $74^{\circ} 6^{\prime} \mathrm{E}$ & 551 \\
\hline G2 & UAS446 & (DWR185/DWR2006//UAS419) & Pune & $18^{\circ} 31^{\prime} \mathrm{N}$ & $73^{\circ} 51^{\prime} \mathrm{E}$ & 562 \\
\hline G3 & HI1605 & $\begin{array}{c}\text { (BOW/VEE/5/ND/VG9144//KAL//BB/3/YACO/4/CHIL/6/ } \\
\text { CASKOR/3/CROC_1/AE.SQ(224)//OPATA/7/PASTOR// } \\
\text { MILAN/KAUZ/3/BAV92 }\end{array}$ & Parbhani & $19^{\circ} 15^{\prime} \mathrm{N}$ & $76^{\circ} 46^{\prime} \mathrm{E}$ & 413 \\
\hline G4 & MACS4087 & $\begin{array}{c}\text { (MACS3125/NG-87(DHTON-23/BIJAGAYELLOW)// } \\
\text { DWR1005 }\end{array}$ & Nashik & $19^{\circ} 59^{\prime} \mathrm{N}$ & $73^{\circ} 47^{\prime} \mathrm{E}$ & 583 \\
\hline G5 & MP1358 & (KACHU²/MUNAL\#1/K1215) & Savalivihir & $19^{\circ} 48^{\prime} \mathrm{N}$ & $74^{\circ} 27^{\prime} \mathrm{E}$ & 519.42 \\
\hline G6 & AKDW2997-16 & (CPAN6140/RAJ1555) & Dharwad & $15^{\circ} 27^{\prime} \mathrm{N}$ & $75^{\circ} 0^{\prime} \mathrm{E}$ & 724 \\
\hline G7 & HI8805 & (IWP5070/HI8638//HI8663) & Bailahongal & $15^{\circ} 48^{\prime} \mathrm{N}$ & $74^{\circ} 51^{\prime} \mathrm{E}$ & 696.61 \\
\hline G8 & UAS472 & $\begin{array}{c}\text { (BIJAGAYELLOW/(YAZI_1/AKAKI_4//SOMAT_3/3/ } \\
\text { AUK/GUIL//GREEN/5) }\end{array}$ & Bagalkot & $16^{\circ} 10^{\prime} \mathrm{N}$ & $75^{\circ} 42^{\prime} \mathrm{E}$ & 524 \\
\hline G9 & MPO1357 & (PDW02/TERTER//GW1133) & & & & \\
\hline G10 & NIAW3170 & (SKOLL/ROLF07) & & & & \\
\hline
\end{tabular}


where $r G_{i}$ and $r W_{i}$ were the rescaled values for yield and WAASB, respectively, for the $i$ th genotype; $G_{i}$ and $W_{i}$ were the yield and the WAASB values for $i$ th genotype. SI superiority index for the $i$ th genotype that weighted between yield and stability, and $\theta_{Y}$ and $\theta_{S}$ were the weights for yield and stability assumed to be of order 65 and 35 respectively in this study,

\begin{tabular}{|c|c|c|}
\hline [8] & Modified AMMI stability Value & MASV $=\sqrt{\sum_{n=1}^{N-1} \frac{\operatorname{SSIPC}_{n}}{\operatorname{SSIPC}_{n+1}}\left(\mathrm{PC}_{n}\right)^{2}+\left(\mathrm{PC}_{n+1}\right)^{2}}$ \\
\hline$[12]$ & Superiority Index & $\mathrm{SI}=\frac{\left(r G_{i} \times \theta_{Y}\right)+\left(r W_{i} \times \theta_{S}\right)}{\left(\theta_{Y}+\theta_{S}\right)}$ \\
\hline [13] & Geometric Adaptability Index & $\mathrm{GAI}=\sqrt[n]{\prod_{k=1}^{n} \bar{X}_{k}}$ \\
\hline [14] & MASV1 & MASV1 $=\sqrt{\sum_{n=1}^{N-1}\left(\frac{\text { SSIPC }_{n}}{\text { SSIPC }_{n+1}} \mathrm{PC}_{n}\right)^{2}+\left(\mathrm{PC}_{n+1}\right)^{2}}$ \\
\hline [15] & $\begin{array}{l}\text { Relative performance of genotypic } \\
\text { values across environments }\end{array}$ & $\mathrm{PRVG}_{i j}=\mathrm{VG}_{i j} / \mathrm{VG}_{i}$ \\
\hline [15] & $\begin{array}{l}\text { Harmonic mean of Relative } \\
\text { performance of genotypic values }\end{array}$ & MHPRVG $_{i}=$ Number of environments $/ \sum_{j=1}^{k}$ \\
\hline
\end{tabular}

AMMI analysis was performed using AMMISOFT version 1.0, available at https://scs.cals.cornell.edu/people/hugh-gauch/ and SAS software version 9.3. Stability measures had been compared with recent analytic measures of adaptability calculated as the relative performance of genetic values (PRVG) and harmonic mean based measure of the relative performance of the genotypic values (MHPRVG) for the simultaneous analysis of stability, adaptability, and yield [16].

\section{Results and Discussion}

\subsection{First-Year 2018-19}

Highly significant effects of the environment (E), GxE interaction, and genotypes $(G)$ had been observed by AMMI analysis. Analysis observed the greater contribution of environments, GxE interactions, and genotypes to the total sum of squares (SS) as compared to the residual effects. Further SS attributable to GxE interactions was partitioned as attributed to GxE interactions Signal and GxE interactions Noise. AMMI analysis is appropriate for data sets where-in SS due to were of magnitude at least of due to additive genotype main effects [4]. The SS for GxE interactions Signal was higher compared to genotype main effects, indicated appropriateness of AMMI analysis. Environment explained about significantly $21.6 \%$ of the total sum of squares due to treatments indicating that diverse environments caused most of the variations in genotypes yield (Table 3). Genotypes explained only $18 \%$ of the total sum of squares, whereas 
$\mathrm{GxE}$ interaction accounted for $21.5 \%$ of treatment variations in yield. Further partitioning of $\mathrm{GxE}$ interaction revealed that the first six multiplicative terms explained $99.3 \%$ of interaction sum of squares and the remaining $0.7 \%$ residual was discarded [17].

\subsubsection{Ranking of Genotypes Vis-à-Vis Number of IPCA's}

The IPCA scores of genotypes in the AMMI analysis indicated the stability or adaptability over environments. The greater the IPCA scores, the more specific adapted is a genotype to certain locations. The more the IPCA scores approximate to zero, the more stable or adapted the genotypes is overall the locations. The ranking of genotype as per absolute IPCA-1 scores were MACS6695, HI8805, HI1605, DBW93 (Table 4). While for IPCA-2, genotypes HI8802, MACS6696, NIDW1149, HI1605 would be of choice. Values of IPCA-3 favoured HI8802, MACS6696, NIDW1149, HI1605 wheat genotypes. As per IPCA-4, UAS446, MACS6696, HI8802, NIDW1149 genotypes would be of stable performance. Values of IPCA-5 favoured HI8802, UAS446, MACS6695, MACS6696 whereas IPCA-6 measure settled for HI8805, MACS6695, DBW93, GW1346 wheat genotypes as far as locations of the zone.

Analytic measures of adaptability MASV and MASV1 consider all IPCAs of the analysis. Genotypes HI8802, UAS446, HI1605, DBW93 had been identified by MASV1 \& MASV measure favoured HI1605, HI8805, UAS446, DBW93 genotypes [14].

Table 3. AMMI analysis of wheat genotypes for restricted irrigation timely sown MET's for 2018-19 \& 2019-20.

\begin{tabular}{|c|c|c|c|c|c|c|}
\hline Source & $\begin{array}{l}\text { Degree of } \\
\text { freedom } \\
18-19\end{array}$ & $\begin{array}{c}\text { Degree of } \\
\text { freedom } \\
19-20\end{array}$ & $\begin{array}{c}\text { Mean Sum } \\
\text { of Squares } \\
18-19\end{array}$ & $\begin{array}{c}\text { Mean Sum } \\
\text { of Squares } \\
19-20\end{array}$ & $\begin{array}{c}\text { Level of } \\
\text { significance } \\
18-19\end{array}$ & $\begin{array}{c}\text { Level of } \\
\text { significance } \\
19-20\end{array}$ \\
\hline Treatments & 95 & 79 & 100.38 & 59.24 & $0.0000000^{* * *}$ & $0.0000000^{* * *}$ \\
\hline Genotypes (G) & 11 & 9 & 255.71 & 86.15 & $0.0000000^{* * *}$ & $0.0000000^{* * *}$ \\
\hline Environments (E) & 7 & 7 & 481.69 & 347.19 & $0.0000000^{* * *}$ & $0.0000000^{* * *}$ \\
\hline Interactions $\mathrm{GxE}$ & 77 & 63 & 43.52 & 23.40 & $0.0000094^{* * *}$ & $0.0000084^{* * *}$ \\
\hline IPC1 & 17 & 15 & 92.90 & 37.18 & $0.0000094^{\star * *}$ & $0.0000084^{* * *}$ \\
\hline IPC2 & 15 & 13 & 39.97 & 28.76 & $0.0378^{*}$ & $0.0020327^{\star *}$ \\
\hline IPC3 & 13 & 11 & 38.14 & 21.72 & 0.1569 & 0.0505548 \\
\hline IPC4 & 11 & 9 & 28.75 & 13.84 & 0.4686 & 0.2425696 \\
\hline IPC5 & 9 & 7 & 30.66 & 16.65 & 0.7027 & 0.3281205 \\
\hline IPC6 & 7 & 5 & 8.94 & 10.31 & 0.9825 & 0.6554473 \\
\hline Residual & 5 & 3 & 4.40 & 3.64 & 0.9586 & 0.7923292 \\
\hline Error & 288 & 240 & 21.10 & 10.54 & & \\
\hline Total & 383 & 319 & 40.77 & 22.60 & & \\
\hline
\end{tabular}


Table 4. Modified AMMI stability values as per significant IPCA's 2018-19.

\begin{tabular}{|c|c|c|c|c|c|c|c|c|c|c|c|}
\hline Genotype & IPCA1 & IPCA2 & IPCA3 & IPCA4 & IPCA5 & IPCA6 & MASV1 & MASV & $\mathrm{R}_{\mathrm{IPCA} 1}$ & $\mathrm{R}_{\text {MASV1 }}$ & $\mathrm{R}_{\text {MASV }}$ \\
\hline NIAW3170 & 1.656 & 1.370 & -1.495 & 0.045 & -1.019 & 0.306 & 7.260 & 4.768 & 9 & 10 & 9 \\
\hline GW1346 & -2.055 & -1.299 & -0.669 & -0.681 & -1.062 & -0.249 & 7.693 & 4.806 & 11 & 11 & 10 \\
\hline MACS4058 & -2.211 & 1.037 & -0.055 & 0.560 & -0.693 & -0.392 & 6.875 & 4.304 & 12 & 9 & 7 \\
\hline DBW93 & 0.409 & -1.359 & 0.101 & -0.126 & 1.038 & 0.246 & 5.278 & 3.226 & 4 & 6 & 4 \\
\hline HI8805 & 0.194 & 0.919 & -0.141 & -1.025 & 0.693 & 0.216 & 3.836 & 2.621 & 2 & 4 & 2 \\
\hline AKDW2997-16 & -1.226 & 0.806 & -0.723 & -0.569 & 1.742 & -0.459 & 8.767 & 4.884 & 8 & 12 & 11 \\
\hline MACS6695 & 0.088 & 0.827 & 2.797 & -0.317 & -0.297 & -0.047 & 5.552 & 4.723 & 1 & 7 & 8 \\
\hline UAS446 & 0.744 & -1.632 & 0.018 & 0.867 & 0.293 & -0.369 & 3.745 & 3.069 & 5 & 2 & 3 \\
\hline HI1605 & 0.346 & -0.605 & 0.233 & 0.148 & -0.766 & -0.399 & 3.757 & 2.117 & 3 & 3 & 1 \\
\hline MACS6696 & 2.036 & -0.343 & -0.057 & -1.323 & -0.359 & -0.217 & 5.982 & 3.954 & 10 & 8 & 6 \\
\hline NIDW1149 & 0.872 & 0.583 & -0.088 & 1.975 & 0.419 & -0.330 & 4.342 & 3.477 & 7 & 5 & 5 \\
\hline HI8802 & -0.853 & -0.305 & 0.079 & 0.446 & 0.011 & 1.695 & 2.938 & 332.830 & 6 & 1 & 12 \\
\hline
\end{tabular}

To identify how the ranks of evaluated wheat genotype altered with utilizing numbers of IPCA in the WAASB estimation, the genotype's ranks were obtained while considering $1,2, \ldots, 7$ IPCA's in the WAASB calculations. WAASB = |IPCA1| for using only first IPCA. The genotype with the smallest WAASB value had been ranked with the first-order. Preferences of wheat genotypes as per W1 were MACS6695, HI8805, HI 1605, DBW93 \& W2 measures found same as MACS6695, HI8805, HI1605, HI8802 as promising genotypes (Table 5). W3 measure settled for HI8805, HI1605, HI8802, DBW93 whereas genotypes HI1605, HI8805, DBW93, HI8802 identified by W4 values. Lastly, W5 observed stable performance of HI1605, HI8802, HI8805, DBW93. Finally, stability measure based on all IPCA's WAASB settled for HI1605, HI8805, HI8802, DBW93 genotypes for considered locations of the zone for stable high yield. The genotypes ranking was altered with use of number of IPCAs were included in the WAASB estimation. This reinforced the benefits of using the WAASB measure as it captured the more variations of IPCAs to compute the stability [12].

\subsubsection{Stable Productive Genotypes by AMMI \& BLUP}

An average yield of genotypes selected NIAW3170, MACS6695, MACS6696, HI1605 wheat genotypes (Table 6). This method is simple, but not fully exploiting all information contained in the dataset. A geometric mean is used to evaluate the adaptability of genotypes and genotypes with high GM will be desirable. Geometric mean top-ranked NIAW3170, MACS6695, MACS6696, HI1605 
Table 5. Weighted average of absolute scores and ranks of wheat genotypes 2018-19.

\begin{tabular}{|c|c|c|c|c|c|c|c|c|c|c|c|c|}
\hline Genotype & W1 & W2 & W3 & W4 & W5 & WAASB & $\mathrm{R}_{\mathrm{W} 1}$ & $\mathrm{R}_{\mathrm{W} 2}$ & $\mathrm{R}_{\mathrm{W} 3}$ & $\mathrm{R}_{\mathrm{W} 4}$ & $\mathrm{R}_{\mathrm{W} 5}$ & $\mathrm{R}_{\text {WAASB }}$ \\
\hline NIAW3170 & 1.656 & 1.570 & 1.553 & 1.336 & 1.294 & 1.257 & 9 & 10 & 11 & 11 & 11 & 11 \\
\hline GW1346 & 2.055 & 1.827 & 1.569 & 1.441 & 1.391 & 1.348 & 11 & 11 & 12 & 12 & 12 & 12 \\
\hline MACS4058 & 2.211 & 1.857 & 1.456 & 1.327 & 1.242 & 1.211 & 12 & 12 & 10 & 10 & 10 & 10 \\
\hline DBW93 & 0.409 & 0.695 & 0.563 & 0.500 & 0.571 & 0.559 & 4 & 5 & 4 & 3 & 4 & 4 \\
\hline HI8805 & 0.194 & 0.412 & 0.351 & 0.448 & 0.481 & 0.471 & 2 & 2 & 1 & 2 & 3 & 2 \\
\hline AKDW2997-16 & 1.226 & 1.100 & 1.016 & 0.951 & 1.057 & 1.034 & 8 & 8 & 8 & 8 & 8 & 8 \\
\hline MACS6695 & 0.088 & 0.310 & 0.865 & 0.786 & 0.721 & 0.696 & 1 & 1 & 7 & 5 & 5 & 5 \\
\hline UAS446 & 0.744 & 1.011 & 0.789 & 0.801 & 0.733 & 0.719 & 5 & 7 & 6 & 6 & 6 & 6 \\
\hline HI1605 & 0.346 & 0.424 & 0.382 & 0.348 & 0.404 & 0.403 & 3 & 3 & 2 & 1 & 1 & 1 \\
\hline MACS6696 & 2.036 & 1.526 & 1.199 & 1.217 & 1.103 & 1.069 & 10 & 9 & 9 & 9 & 9 & 9 \\
\hline NIDW1149 & 0.872 & 0.785 & 0.630 & 0.823 & 0.769 & 0.753 & 7 & 6 & 5 & 7 & 7 & 7 \\
\hline HI8802 & 0.853 & 0.688 & 0.552 & 0.537 & 0.467 & 0.513 & 6 & 4 & 3 & 4 & 2 & 3 \\
\hline
\end{tabular}

$\mathrm{R}_{\mathrm{W} 1}, \mathrm{R}_{\mathrm{W}}, \mathrm{R}_{\mathrm{W} 3}, \mathrm{R}_{\mathrm{W} 4}, \mathrm{R}_{\mathrm{W} 5}, \mathrm{R}_{\mathrm{W} 6}, \mathrm{R}_{\mathrm{WAASB}}=$ Rank of genotypes as per number of IPCA's in WAASB values.

Table 6. Superiority index and adaptability measures of genotypes 2018-19.

\begin{tabular}{ccccccccccccccccccc}
\hline Genotype & AMu & Rk & SI au & Rk & GMu & Rk & SI gu & Rk & HMu & Rk & SI hu & Rk & RPGVu & Rk & MHRPGVu Rk \\
\hline NIAW3170 & 34.28 & 1 & 68.37 & 3 & 34.12 & 1 & 68.37 & 3 & 33.97 & 1 & 68.37 & 4 & 1.1136 & 1 & 1.1017 & 1 \\
GW1346 & 27.82 & 12 & 0.00 & 12 & 27.34 & 12 & 0.00 & 12 & 26.80 & 12 & 0.00 & 12 & 0.8950 & 12 & 0.8794 & 12 \\
MACS4058 & 29.44 & 9 & 21.43 & 11 & 29.24 & 9 & 23.26 & 11 & 29.01 & 9 & 25.19 & 11 & 0.9537 & 9 & 0.9439 & 9 \\
DBW93 & 30.46 & 7 & 55.84 & 7 & 30.14 & 7 & 56.05 & 7 & 29.78 & 7 & 56.32 & 7 & 0.9796 & 7 & 0.9767 & 7 \\
HI8805 & 31.05 & 6 & 65.04 & 4 & 30.96 & 6 & 67.17 & 4 & 30.86 & 6 & 69.33 & 3 & 1.0056 & 6 & 1.0039 & 6 \\
AKDW2997-16 & 29.20 & 10 & 25.55 & 10 & 29.00 & 10 & 27.54 & 9 & 28.78 & 10 & 29.60 & 9 & 0.9450 & 10 & 0.9374 & 10 \\
MACS6695 & 33.73 & 2 & 83.69 & 1 & 33.54 & 2 & 83.56 & 1 & 33.36 & 2 & 83.64 & 1 & 1.0932 & 2 & 1.0839 & 2 \\
UAS446 & 28.24 & 11 & 27.54 & 9 & 27.72 & 11 & 26.96 & 10 & 27.14 & 11 & 26.39 & 10 & 0.9042 & 11 & 0.8951 & 11 \\
HI1605 & 32.33 & 4 & 80.36 & 2 & 32.13 & 4 & 80.87 & 2 & 31.92 & 4 & 81.41 & 2 & 1.0433 & 4 & 1.0421 & 4 \\
MACS6696 & 33.20 & 3 & 64.46 & 5 & 32.91 & 3 & 63.73 & 6 & 32.63 & 3 & 63.18 & 6 & 1.0728 & 3 & 1.0637 & 3 \\
NIDW1149 & 32.02 & 5 & 64.29 & 6 & 31.85 & 5 & 65.24 & 5 & 31.67 & 5 & 66.24 & 5 & 1.0349 & 5 & 1.0323 & 5 \\
HI8802 & 29.80 & 8 & 50.92 & 8 & 29.47 & 8 & 51.38 & 8 & 29.08 & 8 & 51.62 & 8 & 0.9591 & 8 & 0.9538 & 8 \\
\hline
\end{tabular}

$\mathrm{AMu}, \mathrm{GMu}, \mathrm{HMu}=$ Arithmetic, Geometric, Harmonic Mean for BLUP values; SI au, SI gu, SI hu = Superiority index as per Arithmetic, Geometric, Harmonic Mean; RPGVu, MHRPGVu = Relative performance and Harmonic mean of Relative Performance as per BLUP of genotypes; Rk = Rank of genotypes. 
genotypes. As proposed by Resende [6], a method to rank genotypes considering the yield and stability simultaneously is the harmonic mean of genetic values (HMGV). In the context of mixed models, the Harmonic Mean of Genotypic Values was calculated as genotypes with greater values would be recommended. Harmonic Mean expressed higher values for NIAW3170, MACS6695, MACS6696, HI1605 genotypes. Moreover, the Harmonic Mean of Relative Performance of Genotypic Values (HMRPGV) method proposed by Resende \& Durate [15] that used Restricted Maximum Likelihood (REML) or Best Linear Unbiased Prediction (BLUP) as similar to the methods of Lin and Binns [2] and Annicchiarico [18]. In the HMRPGV method for stability analysis, the genotypes can be simultaneously sorted by genotypic values (yield) and stability using the harmonic means of the yield so that the smaller the standard deviation of genotypic performance among the locations. Values of HMRPGV ranked NIAW3170, MACS6695, MACS6696, HI1605 the performance of the genotypes among the locations. When considering the yield and adaptability simultaneously, the recommended approach is the relative performance of genetic values (RPGV) overcrop years. For adaptability analysis, the Relative Performance of Genotypic Values had measured across environments. Relative Performance of Genotypic Values had settled for NIAW3170, MACS 6695, MACS6696, HI1605 wheat genotypes.

While assigning 65 and 35 weights to average yield (AM) and stability, the Superiority index pointed out MACS6695, HI1605, NIAW3170, HI8805 genotypes would maintain high yield and stable performance. SI measure considered GM and stability, selected MACS6695, HI 1605, NIAW3170, HI8805 genotypes. Values of SI, using HM and stability, favoured the same set of wheat genotypes MACS6695, HI1605, HI8805, NIAW3170. Analytic measures of adaptability RPGV and MHRPGV pointed out MACS6695, HI1605, NIAW3170, HI8805 would be more adaptable genotypes.

\subsubsection{Biplot Analysis of Measures}

Approximately $74.2 \%$ of the total variation (Table 7) with $46.2 \& 27.9$ contributions of the first two significant PC's was observed in the principal component analysis of stability measures [19]. The first group comprised of MASV1 \& stability measures by utilizing the number of interaction principal components (Figure 1). MASV clustered with IPCA4, IPCA5, and IPCA6 values in a different quadrant. Adaptability measures as per arithmetic, geometric and harmonic means along with the corresponding values of RPGV \& MHRPGV measures expressed bondage and placed all together in a different quadrant. However, this group maintained the right angle with MASV1 \& stability measures. The cluster of Superiority indexes as per various averages of yield seen in same quadrant. Moreover, the performance of genotypes would be more or less the same by $\mathrm{Su}$ periority indexes and adaptability measures as acute angles observed in corresponding rays. 


\subsection{Second-Year 2019-20}

Highly significant effects of the environment (E), GxE interaction, and genotypes $(\mathrm{G})$ had been observed by AMMI analysis. Environment explained significantly $33.7 \%$, GxE interaction accounted for $20.5 \%$ and genotypes contributed only $10.7 \%$ of the total sum of squares due to treatments (Table 3). First six multiplicative terms explained $99.3 \%$ of $\mathrm{GxE}$ interaction and $0.7 \%$ was the residual or noise.

Table 7. Loadings of measures as per first two significant principal components (2018-19).

\begin{tabular}{|c|c|c|}
\hline Measure & PC1 & PC2 \\
\hline IPCA1 & -0.1843 & -0.1544 \\
\hline IPCA2 & -0.0552 & -0.2234 \\
\hline IPCA3 & -0.1527 & 0.0456 \\
\hline IPCA4 & -0.0249 & 0.0876 \\
\hline IPCA5 & -0.0445 & 0.1903 \\
\hline IPCA6 & -0.0856 & 0.1048 \\
\hline MASV1 & 0.2015 & -0.2060 \\
\hline MASV & -0.0369 & 0.1638 \\
\hline W1 & 0.2423 & -0.1832 \\
\hline W2 & 0.2617 & -0.1705 \\
\hline W3 & 0.2294 & -0.2453 \\
\hline W4 & 0.2316 & -0.2446 \\
\hline W5 & 0.2409 & -0.2407 \\
\hline W6 & 0.2438 & -0.2353 \\
\hline WAASB & 0.2438 & -0.2353 \\
\hline $\mathrm{AMu}$ & -0.2107 & -0.2847 \\
\hline SI au & -0.2901 & -0.1252 \\
\hline $\mathrm{GMu}$ & -0.2119 & -0.2839 \\
\hline SI gu & -0.2908 & -0.1231 \\
\hline $\mathrm{HMu}$ & -0.2122 & -0.2833 \\
\hline SI hu & -0.2910 & -0.1215 \\
\hline RPGVu & -0.2061 & -0.2908 \\
\hline MHRPGVu & -0.2173 & -0.2771 \\
\hline$\%$ variation explained & 46.23 & 27.97 \\
\hline
\end{tabular}




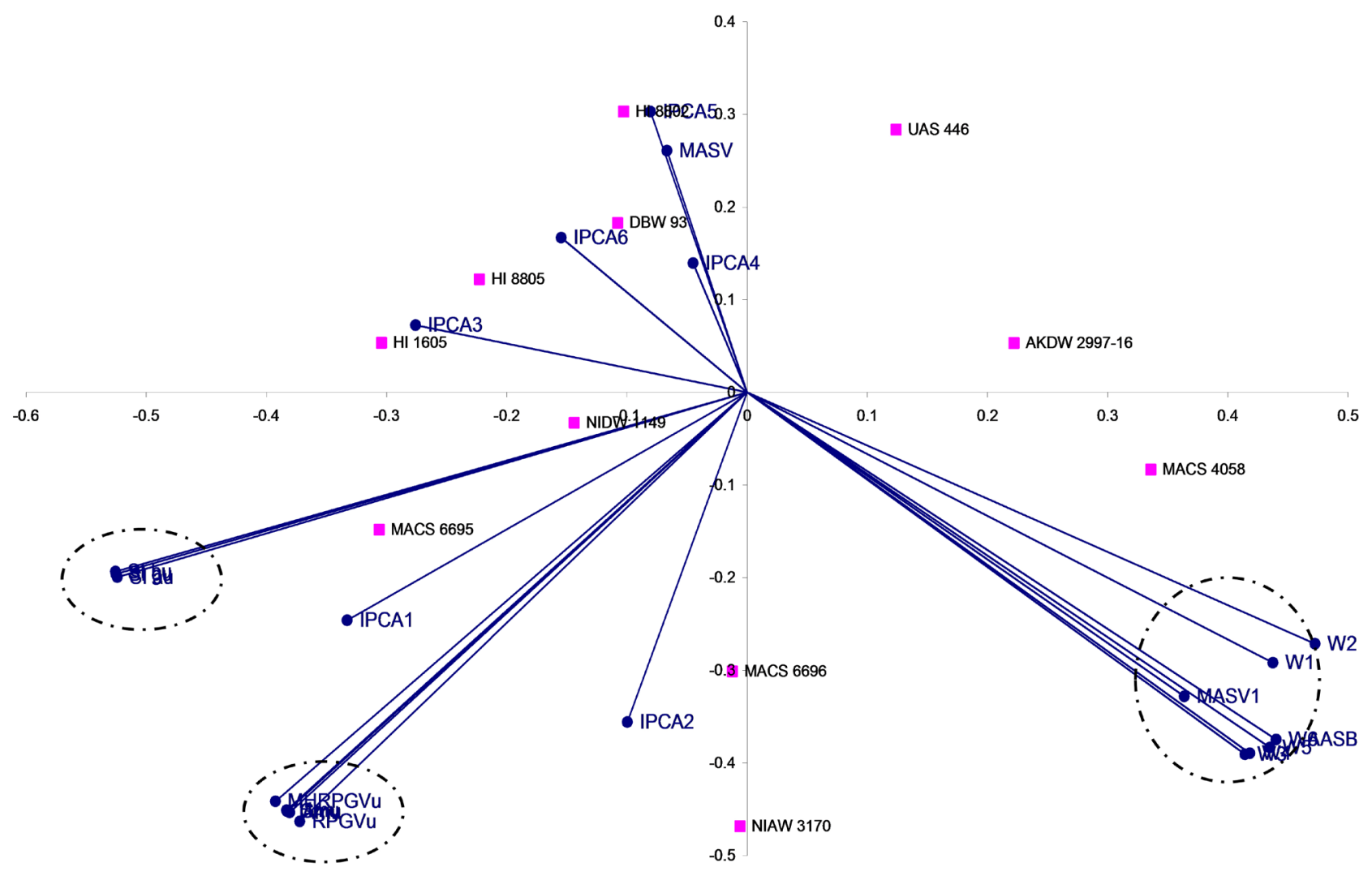

Figure 1. Biplot analysis of stability measures as per first two significant PCA's (2018-19).

\subsubsection{Ranking of Genotypes Vis-à-Vis Number of IPCA's}

The preference order of genotypes as per IPCA-1 scores were MP1358, NIAW3170, NIDW1149, HI8805 (Table 8). While the values of IPCA-2 selected MACS4087, MPO1357, HI8805, MP1358 genotypes would be of choice. Values of IPCA-3 favoured UAS446, HI1605, AKDW2997-16, NIDW1149 wheat genotypes. As per IPCA-4, HI1605, UAS446, NIDW1149, NIAW3170 genotypes would be of stable performance. UAS472, MACS4087, NIDW1149, UAS446 genotypes pointed by IPCA-5 measure. Genotypes MACS4087, AKDW2997-16, HI1605, MP1358 identified by absolute values of IPCA-6. Analytic MASV and MASV1 measures of adaptability considered all significant IPCAs of the analysis simultaneously. MASV1 identified genotypes NIAW3170, UAS472, UAS446, and NIDW1149 would express stable yield whereas genotypes UAS472, NIAW3170, UAS446 \& AKDW2997-16 be of stable performance by MASV measure respectively.

Genotype preferences varied from MP1358, NIAW3170, NIDW1149, HI8805 based on W1 whereas MP1358, HI8805, AKDW2997-16, NIAW3170 as per W2 values while AKDW2997-16, MP1358, HI8805, NIAW3170 by values of W3 (Table 9). Genotypes AKDW2997-16, MP1358, NIAW3170, HI8805 were pointed by W4; W5 favoured AKDW2997-16, MP1358, UAS472, NIAW3170. Stability measure WAASB based on all significant IPCA's settled for AKDW2997-16, MP1358 NIAW3170, UAS472 genotypes for considered locations of the zone for 
stable high yield. The ranking of genotypes were altered by the extent to the number of IPCAs included in the WAASB estimation.

\subsubsection{Stable productive genotypes by AMMI \& BLUP}

Average yield of genotypes selected MP1358, NIDW1149, HI1605, MACS4087 wheat genotypes (Table 10). Geometric mean observed MP1358, HI1605, NIDW1149, MACS4087 were top-ranked genotypes. Harmonic Mean of yield expressed higher values for MP1358, HI1605, NIDW1149, MACS4087 genotypes. Values of HMRPGV ranked MP1358, NIDW1149, HI1605, MACS4087 the genotypes performance among the locations. Relative Performance of Genotypic Values had settled for MP1358, HI1605, NIDW1149, MACS4087 wheat genotypes.

Table 8. Modified AMMI stability values as per significant IPCA's 2019-20.

\begin{tabular}{|c|c|c|c|c|c|c|c|c|c|c|c|}
\hline Genotype & IPCA1 & IPCA2 & IPCA3 & IPCA4 & IPCA5 & IPCA6 & MASV1 & MASV & $\mathrm{R}_{\mathrm{IPCA1}}$ & $\mathrm{R}_{\text {MASV1 }}$ & $\mathrm{R}_{\text {MASV }}$ \\
\hline NIDW1149 & -0.121 & 2.521 & -0.347 & -0.112 & 0.292 & -0.767 & 3.922 & 3.784 & 3 & 4 & 9 \\
\hline HI1605 & 2.205 & 0.528 & 0.247 & -0.045 & -0.648 & 0.440 & 4.417 & 3.275 & 10 & 5 & 5 \\
\hline MACS4087 & -1.528 & 0.000 & 1.308 & -0.422 & -0.255 & 0.244 & 4.827 & 3.346 & 9 & 6 & 6 \\
\hline MP1358 & 0.058 & -0.227 & -1.064 & -1.184 & 1.067 & 0.445 & 6.399 & 3.627 & 1 & 8 & 7 \\
\hline AKDW2997-16 & -0.424 & -0.276 & 0.339 & -1.118 & -0.686 & 0.421 & 5.588 & 2.945 & 5 & 7 & 4 \\
\hline HI8805 & 0.352 & 0.206 & 0.984 & 1.232 & 1.013 & 0.805 & 6.589 & 3.720 & 4 & 9 & 8 \\
\hline UAS472 & -0.944 & -0.473 & 0.712 & 0.354 & -0.092 & -0.848 & 3.239 & 2.295 & 6 & 2 & 1 \\
\hline MPO1357 & -1.138 & -0.013 & -1.661 & 1.019 & -0.974 & 0.487 & 6.852 & 4.314 & 7 & 10 & 10 \\
\hline NIAW3170 & 0.092 & -1.318 & -0.592 & 0.223 & 0.914 & -0.524 & 2.856 & 2.480 & 2 & 1 & 2 \\
\hline
\end{tabular}

Table 9. Weighted average of absolute scores and ranks of genotypes 2019-20.

\begin{tabular}{cccccccccccccc}
\hline Genotype & $\mathrm{W} 1$ & $\mathrm{~W} 2$ & $\mathrm{~W} 3$ & $\mathrm{~W} 4$ & $\mathrm{~W} 5$ & $\mathrm{WAASB}$ & $\mathrm{R}_{\mathrm{W} 1}$ & $\mathrm{R}_{\mathrm{W} 2}$ & $\mathrm{R}_{\mathrm{W} 3}$ & $\mathrm{R}_{\mathrm{W} 4}$ & $\mathrm{R}_{\mathrm{W} 5}$ & $\mathrm{R}_{\mathrm{WAASB}}$ \\
\hline NIDW1149 & 0.121 & 1.168 & 0.964 & 0.848 & 0.770 & 0.770 & 3 & 8 & 8 & 7 & 6 & 7 \\
UAS446 & 1.448 & 1.230 & 0.944 & 0.822 & 0.795 & 0.788 & 8 & 9 & 7 & 6 & 7 & 8 \\
HI1605 & 2.205 & 1.473 & 1.169 & 1.016 & 0.964 & 0.922 & 10 & 10 & 10 & 10 & 10 & 10 \\
MACS4087 & 1.528 & 0.862 & 0.972 & 0.897 & 0.807 & 0.761 & 9 & 7 & 9 & 8 & 8 & 6 \\
MP1358 & 0.058 & 0.132 & 0.363 & 0.475 & 0.558 & 0.549 & 1 & 1 & 2 & 2 & 2 & 2 \\
AKDW2997-16 & 0.424 & 0.360 & 0.354 & 0.459 & 0.491 & 0.485 & 5 & 3 & 1 & 1 & 1 & 1 \\
HI8805 & 0.352 & 0.288 & 0.461 & 0.566 & 0.629 & 0.643 & 4 & 2 & 3 & 4 & 5 & 5 \\
UAS472 & 0.944 & 0.738 & 0.732 & 0.680 & 0.597 & 0.617 & 6 & 6 & 5 & 5 & 3 \\
MPO1357 & 1.138 & 0.647 & 0.899 & 0.915 & 0.923 & 0.888 & 7 & 5 & 6 & 9 & 9 \\
NIAW3170 & 0.092 & 0.627 & 0.618 & 0.564 & 0.614 & 0.606 & 2 & 4 & 4 & 3 & 4 \\
\hline
\end{tabular}


While assigning 65 and 35 weights to average yield (AM) and stability, the Superiority index pointed out MP1358, NIAW3170, NIDW1149, MACS4087 genotypes would maintain high yield and stable performance. SI measure considered GM and stability, selected MP1358, NIAW3170, NIDW1149, MACS4087 genotypes. Values of SI, using HM and stability, favoured the same set of wheat genotypes MP1358, NIAW3170, NIDW1149, AKDW2997-16. Analytic measures of adaptability RPGV and MHRPGV pointed out MP1358, HI1605, NIDW1149, MACS4087 would be more adaptable genotypes.

\subsubsection{Biplot Analysis of Measures}

Loadings of the stability measures of wheat genotypes were tabulated and the first two significant PC's has explained $68.7 \%$ of the total variation in the original variables with $41.1 \& 27.6$ percent respective contributions (Table 11). Three groups of measures were observed in graphical Biplot analysis (Figure 2). The first group comprised of stability measures by utilizing the number of interaction principal components. Adaptability measures as per arithmetic, geometric and harmonic means and their corresponding values expressed deviation and observed in a different quadrant. Moreover, this group maintained the right angle with stability measures. The cluster of Superiority indexes as per averages yield of wheat genotypes placed in a different quadrant. Performance of genotypes would not be different by Superiority indexes and adaptability measures due to acute angles among rays connecting corresponding measures.

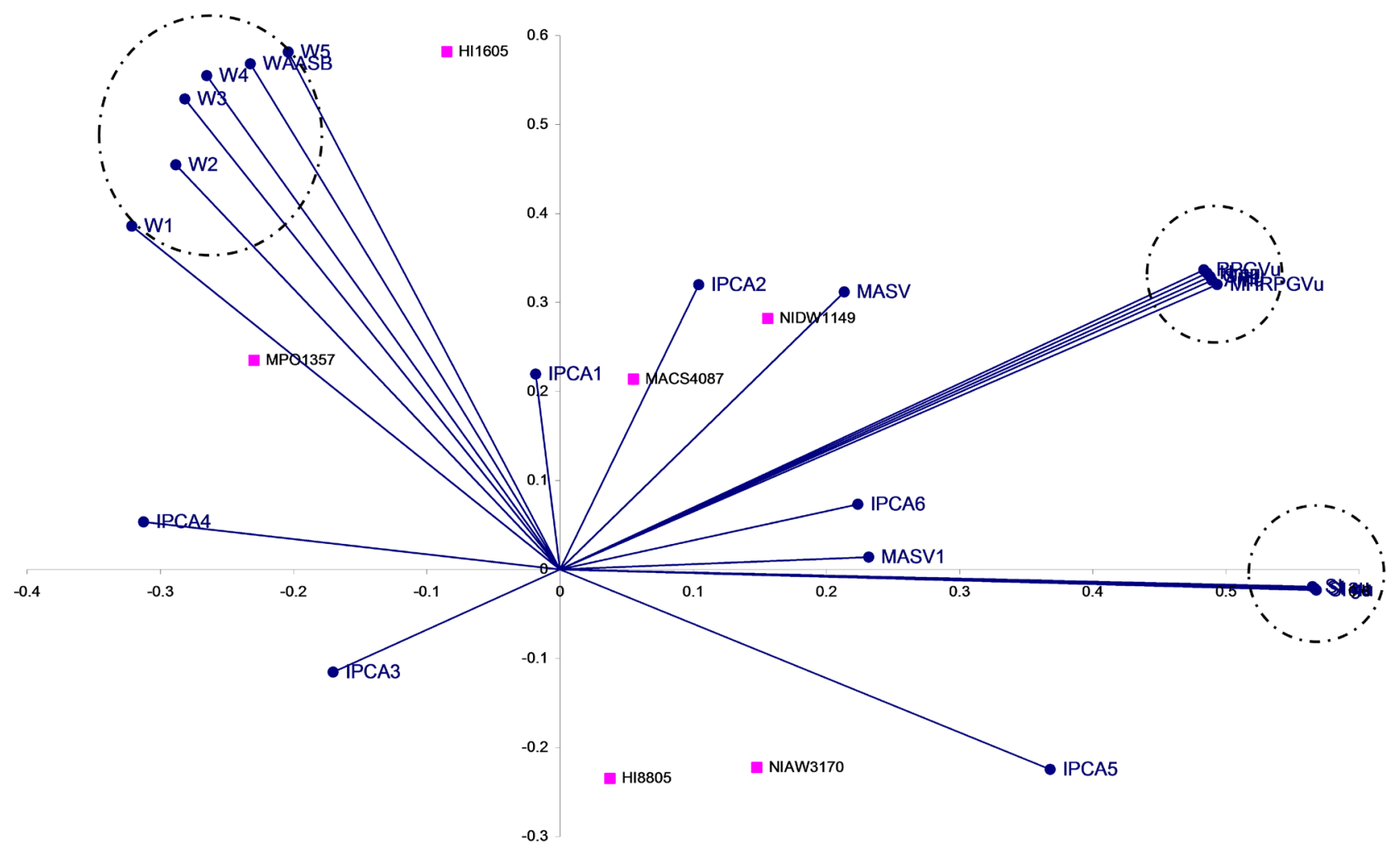

Figure 2. Biplot analysis of stability measures as per first two significant PCA's (2019-20). 
Table 10. Superiority index and adaptability measures of genotypes 2019-20.

\begin{tabular}{|c|c|c|c|c|c|c|c|c|c|c|c|c|c|c|c|c|}
\hline Genotype & $\mathrm{AMu}$ & Rk & SI au & $\mathrm{Rk}$ & $\mathrm{GMu}$ & $\mathrm{Rk}$ & SI gu & $\mathrm{Rk}$ & $\mathrm{HMu}$ & $\mathrm{Rk}$ & SI hu & Rk & RPGVu & $\mathrm{Rk}$ & MHRPGVu & $\mathrm{Rk}$ \\
\hline NIDW1149 & 25.78 & 2 & 59.63 & 3 & 25.51 & 3 & 58.64 & 3 & 25.24 & 3 & 57.72 & 3 & 1.036 & 3 & 1.030 & 2 \\
\hline UAS446 & 23.82 & 9 & 26.69 & 9 & 23.67 & 9 & 27.95 & 9 & 23.52 & 9 & 29.33 & 9 & 0.961 & 9 & 0.956 & 9 \\
\hline HI1605 & 25.69 & 3 & 45.94 & 7 & 25.52 & 2 & 46.67 & 7 & 25.36 & 2 & 47.44 & 7 & 1.037 & 2 & 1.029 & 3 \\
\hline MACS4087 & 25.63 & 4 & 57.85 & 4 & 25.32 & 4 & 56.27 & 4 & 24.98 & 4 & 54.39 & 5 & 1.028 & 4 & 1.022 & 4 \\
\hline MP1358 & 26.88 & 1 & 94.88 & 1 & 26.68 & 1 & 94.88 & 1 & 26.48 & 1 & 94.88 & 1 & 1.082 & 1 & 1.079 & 1 \\
\hline AKDW2997-16 & 24.06 & 8 & 54.75 & 5 & 23.84 & 8 & 54.90 & 5 & 23.62 & 8 & 55.10 & 4 & 0.966 & 8 & 0.964 & 8 \\
\hline HI8805 & 24.36 & 7 & 46.89 & 6 & 24.16 & 7 & 47.41 & 6 & 23.97 & 7 & 47.98 & 6 & 0.980 & 7 & 0.977 & 7 \\
\hline UAS472 & 22.83 & 10 & 24.39 & 10 & 22.59 & 10 & 24.39 & 10 & 22.34 & 10 & 24.39 & 10 & 0.917 & 10 & 0.912 & 10 \\
\hline MPO1357 & 24.38 & 6 & 27.67 & 8 & 24.24 & 6 & 28.91 & 8 & 24.09 & 6 & 30.23 & 8 & 0.983 & 6 & 0.980 & 6 \\
\hline NIAW3170 & 25.09 & 5 & 61.63 & 2 & 24.91 & 5 & 62.16 & 2 & 24.71 & 5 & 62.58 & 2 & 1.010 & 5 & 1.007 & 5 \\
\hline
\end{tabular}

Table 11. Loadings of measures as per first two significant principal components (2019-20).

\begin{tabular}{|c|c|c|}
\hline Measure & PC1 & PC2 \\
\hline IPCA1 & -0.0105 & 0.1397 \\
\hline IPCA2 & 0.0601 & 0.2038 \\
\hline IPCA3 & -0.0982 & -0.0735 \\
\hline IPCA4 & -0.1802 & 0.0339 \\
\hline IPCA5 & 0.2123 & -0.1431 \\
\hline IPCA6 & 0.1290 & 0.0466 \\
\hline MASV1 & 0.1337 & 0.0088 \\
\hline MASV & 0.1231 & 0.1986 \\
\hline W1 & -0.1853 & 0.2457 \\
\hline W2 & -0.1662 & 0.2895 \\
\hline W3 & -0.1623 & 0.3366 \\
\hline W4 & -0.1528 & 0.3534 \\
\hline W5 & -0.1176 & 0.3703 \\
\hline WAASB & -0.1340 & 0.3619 \\
\hline $\mathrm{AMu}$ & 0.2822 & 0.2068 \\
\hline SI au & 0.3257 & -0.0124 \\
\hline $\mathrm{GMu}$ & 0.2814 & 0.2095 \\
\hline SI gu & 0.3268 & -0.0136 \\
\hline $\mathrm{HMu}$ & 0.2801 & 0.2121 \\
\hline SI hu & 0.3274 & -0.0149 \\
\hline RPGVu & 0.2788 & 0.2143 \\
\hline MHRPGVu & 0.2845 & 0.2039 \\
\hline$\%$ variation explained & 41.15 & 27.62 \\
\hline
\end{tabular}




\section{Conclusion}

GxE interaction study in multi-environment trials had been carried out by well established AMMI model. The simultaneous consideration of stability measures and yield would be more appropriate to recommend high-yielding stable wheat genotypes. In the present study, the main advantages of AMMI and BLUP had been combined to increase the reliability of multi-locations trials analysis. An additional advantage provided by Superority Indexes to assign variable weights to the yield and stability performance. Depending upon the goal of crop breeding trials, the researchers may prioritize the productivity of a genotype rather than its stability (and vice-versa). The stability index of genotype performance has the potential to provide reliable estimates of stability in future studies along with a joint interpretation of performance and stability in a biplot while considering number of significant IPCA's.

\section{Acknowledgements}

The wheat genotypes were evaluated at research fields at coordinated centers of AICW\&BIP across the country. The first author sincerely acknowledges the hard work of all the staff for field evaluation and data recording of wheat genotypes.

\section{Conflicts of Interest}

The authors declare no conflicts of interest regarding the publication of this paper.

\section{References}

[1] Agahi, K., Ahmadi, J., Oghan, H.A., Fotokian, M.H. and Orang, S.F. (2020) Analysis of Genotype $\times$ Environment Interaction for Seed Yield in Spring Oilseed Rape Using the AMMI Model. Crop Breeding and Applied Biotechnology, 20, e26502012. https://doi.org/10.1590/1984-70332020v20n1a2

[2] Lin, C.S. and Binns, M.R. (1988) A Superiority Measure of Cultivar Performance for Cultivar x Location Data. Canadian Journal of Plant Science, 68, 193-198. https://doi.org/10.4141/cjps88-018

[3] Bocianowski, J., Niemann, J. and Nowosad, K. (2019) Genotype-By Environment Interaction for Seed Quality Traits in Interspecific Cross-Derived Brassica Lines Using Additive Main Effects and Multiplicative Interaction Model. Euphytica, 215, 7. https://doi.org/10.1007/s10681-018-2328-7

[4] Gauch, H.G. (2013) A Simple Protocol for AMMI Analysis of Yield Trials. Crop Science, 53, 1860-1869. https://doi.org/10.2135/cropsci2013.04.0241

[5] Piepho, H.P., Mohring, J., Melchinger, A.E. and Buchse, A. (2008) BLUP for Phenotypic Selection in Plant Breeding and Variety Testing. Euphytica, 161, 209-228. https://doi.org/10.1007/s10681-007-9449-8

[6] Resende, M.D.V. (2007) Software Selegen-REML/BLUP: Sistema estatístico e seleção genética computadorizada via modelos lineares mistos. Embrapa Florestas, Colombo, $350 \mathrm{p}$.

[7] Ajay, B.C., Bera, S.K., Singh, A.L., Kumar, N., Gangadhar, K. and Kona, P. (2020) 
Evaluation of Genotype $\times$ Environment Interaction and Yield Stability Analysis in Peanut under Phosphorus Stress Condition Using Stability Parameters of AMMI Model. Agricultural Research, 9, 477-486.

https://doi.org/10.1007/s40003-020-00458-3

[8] Zali, H., Farshadfar, E., Sabaghpour, S.H. and Karimizadeh, R. (2012) Evaluation of Genotype $\times$ Environment Interaction in Chickpea Using Measures of Stability from AMMI Model. Annals of Biological Research, 3, 3126-3136.

[9] Farshadfar, E. (2008) Incorporation of AMMI Stability Value and Grain Yield in a Single Non-Parametric Index (GSI) in Bread Wheat. Pakistan Journal of Biological Sciences, 11, 1791-1796. https://doi.org/10.3923/pjbs.2008.1791.1796

[10] Farshadfar, E., Mahmodi, N. and Yaghotipoor, A. (2011) AMMI Stability Value and Simultaneous Estimation of Yield and Yield Stability in Bread Wheat (Triticum aestivum L.). Australian Journal of Crop Science, 5, 1837-1844.

[11] Rao, A.R. and Prabhakaran, V.T. (2005) Use of AMMI in Simultaneous Selection of Genotypes for Yield and Stability. Journal of the Indian Society of Agricultural Statistics, 59, 76-82.

[12] Olivoto, T., et al. (2019) Mean Performance and Stability in Multi-Environment Trials I: Combining Features of AMMI and BLUP Techniques. Agronomy Journal, 111, 1-12. https://doi.org/10.2134/agronj2019.03.0220

[13] Mohammadi, R. and Amri, A. (2008) Comparison of Parametric and Non-Parametric Methods for Selecting Stable and Adapted Durum Wheat Genotypes in Variable Environments. Euphytica, 159, 419-432.

https://doi.org/10.1007/s10681-007-9600-6

[14] Ajay, B.C., Aravind, J., Fiyaz, R.A., Kumar, N., Lal, C., Kona, P., Dagla, M.C. and Bera, S.K. (2019) Rectification of Modified AMMI Stability Value (MASV). Indian Journal of Genetics \& Plant Breeding, 79, 726-731.

[15] Resende, M.D.V. and Duarte, J.B. (2007) Precision and Quality Control in Variety Trials. Pesquisa Agropecuaria Tropical, 37, 182-194.

[16] Mendes, F.F., Guimarães, L.J.M., Souza, J.C., Guimarães, P.E.O., Pacheco, C.A.P., Machado, J.R.A., Meirelles, W.F., Silva, A.R. and Parentoni, S.N. (2012) Adaptability and Stability of Maize Varieties Using Mixed Model Methodology. Crop Breeding and Applied Biotechnology, 12, 111-117. https://doi.org/10.1590/S1984-70332012000200003

[17] Oyekunle, M., Menkir, A., Mani, H., Olaoye, G., Usman, I.S. and Ado, S. (2017) Stability Analysis of Maize Cultivars Adapted to Tropical Environments Using AMMI Analysis. Cereal Research Communications, 45, 336-345. https://doi.org/10.1556/0806.44.2016.054

[18] Annicchiarico, P. (1992) Cultivar Adaptation and Recommendation from Alfalfa Trials in Northern Italy. Journal of Genetics and Plant Breeding, 46, 269-278.

[19] Mohammadi, M., Sharifi, P., Karimizadeh, R., Jafarby, J.A., Khanzadeh, H., Hosseinpour, T., Poursiabidi, M.M., Roustaii, M., Hassanpour, H.M. and Mohammadi, P. (2015) Stability of Grain Yield of Durum Wheat Genotypes by AMMI Model. Agriculture and Forestry, 61, 181-193.

https://doi.org/10.17707/AgricultForest.61.3.18 